\title{
ASISTIVNI ROBOTI U RADU SA DECOM: KAKO IH VIDE DECA I RODITELJI
}

Rezime: Prvi cilj ovog istraživanja je da se odgovori na pitanje da li postoji razlika u preferenciji različitih modela robota kod dece, kao i da li postoji razlika u zastupljenosti različitih boja kojima deca boje modele? Drugi cilj istraživanja je da se odgovori na pitanje da li postoje polne razlike u preferenciji različitih modela kod dece, kao i u pripisuvanju pola robotu, dok je treći cilj istraživanja da se odgovori na pitanje da li postoji razlika u stavu prema robotu kod roditelja u zavisnosti od stručne spreme, pola i starosti? Učenici prvih razreda iz sedam osnovnih škola sa teritorije Južnobačkog okruga su učestvovali u istraživanju u kom su procenjivani prikazani modeli robota. Roditelji dece su odgovarali na upitnik o stavovima prema robotu kao asistivnom sredstvu. Rezultati pokazuju da deca imaju preferenciju prema modelima animalnog izgleda sa prenaglašenim facijalne crtama nalik crtanim likovima koji deluju kompaktno i zdepasto. Takođe, uočene su polne razlike u preferenciji modela i pripisivanju pola robotima. U odnosu na boje kojima su deca obojili modele, dominantna boja je bila plava, kao i razne kombinacije koje obuhvataju plavu boju. U mišljenju roditelja prevladava više pozitivan nego negativan stav prema robotu kao pomagaču.

Ključne reči: dečija preferencija robota, pol, uzrast, stav roditelja prema asistivnom robotu

\section{UVOD}

Razvoj robotike se odvija brzinom koja je zapanjujuća - nove metode i novi algoritmi su razvijani zapanjujućim intenzitetom i zahvaljujući ovom razvoju moderni roboti stiču sve veću autonomnost. Međutim, to što se često gubi iz vida je da sam razvoj robotike i nova otkrića na tehničkom planu nisu dovoljna da bi se postigao uspeh, već je neophodno uzeti u obzir i psihofizičke karakteristike korisnika 
robota.

Rezultati prethodnih istraživanja pokazuju da korisnici često imaju poteškoća sa konceptualizacijom robota (Giuliani i sar, 2003). koncept robota najčešće nije dovoljno jasno definisan, postavljaju se prevelika ili premala očekivanja u odnosu na mogućnosti i ograničenja robota. Primena robota u svrhe pomaganja ljudima u rešavanju raznih zadataka u velikom broju slučajeva se ne implementira iz razloga koji nisu tehničke prirode, već psihološke: na primer, strah od korišćenja robota, neadekvatan trening potencijalnih korisnika, nedovoljno razumevanje potencijalnih koristi od primene asistivne tehnologije, itd. Zbog toga se javlja potreba za detaljnijom analizom psiholoških karakteristika potencijalnih korisnika, pre svega njihovih stavova i očekivanja vezanih za korišćenje robota u svakodnevnom životu. Velik broj argumenata govori u prilog korišćenju robota. Doughty (1999) kao prednosti korišćenja robota ističe da, za razliku od ljudi, roboti pomagači mogu da pruže kontinuiranu negu, objektivni su u analizi i proceni, ne umaraju se i nikada nisu neraspoloženi. Sa druge strane, često se ističe da, iako postoje brojne prednosti u primeni robota u radu sa ljudima, prisutan je i značajan nedostatak: roboti ne mogu da pruže emotivnu podršku koja je nezaobilazni deo socijalne interakcije sa ljudima.

Nauka je danas razvila robote koji su skoro u potpunosti identični čoveku, kako u izgledu, tako i u ponašanju. Na primer, roboti današnjice mogu da učestvuju u dijalogu sa korisnikom, prate ponašanje korisnika kao što su gestovi i pogled korisnika (Fong i Nourbahkshk, 2003). Međutim, funkcionalnost robota se ipak ne može posmatrati odvojeno od stava korisnika prema robotu. Ipak, iako su mnogi korisnici skeptični prema korišćenju robota (npr., Gitlin, 1995), čini se da kod većine korisnika ipak prevladavaju pozitivni stavovi (Heerink i sar, 2009). Istraživanja pokazuju da su ljudi generalno skloni pripisivanju intencionalnosti neživim entitetima, te pripisivanju pola i socijalnih uloga robotima i skloni su da stupe u interakciju sa robotom (Nass i Moon, 2000). Od robota se često čak očekuje reciproceitet i učtivost (Nass i Moon, 2000). Ljudi su skloni antropomorfizaciji neživih entiteta time što im pripisuju emotivne i kognitivne procese svojstvene entitetima koji su vođeni principom racionalne akcije (Duffy, 2003; Csibra i Gergely, 2007). Rezultati istraživanja Bumby i Dautenhahn (1999) pokazuju da su i deca i odrasli skloni percepciji robota kao entiteta sa slobodnom voljom, preferencijama, emocijama, i pre svega muškog pola. Specifični fizički atributi robota su asocirani sa određenim crtama ličnosti robota, kao 
i emotivnim stanjima (Woods i sar, 2004). Rezultati istraživanja Woods i saradnika (2004) pokazuju da su roboti koji imaju izdužen torzo sa tankim nogama i rukama, koji su nalik mašini i koji su muškog pola procenjivani od strane dece kao roboti koji su skloni negativnim ponašanjima. Sa druge strane, roboti animalnog izgleda koji deluju zdepasto, i koji imaju prenaglašene crte lica nalik crtanim likovima i ženskog su pola, asocirani su sa pozitivnim emocijama i pozitivnim ponašanjem. Roboti koji su potpuno animalnog izgleda su procenjivani pozitivnije u odnosu na robote koji su potpuno nalik mašini ili potpuno čovekoliki. Roboti koji su mešavina fizičkih karakteristika mašine i čoveka su procenjivani najpozitivnije. Woods i sar. (2004) zaključuju da je preporučljivo da roboti koji su namenjeni izazivanju pozitivnih emocionalnih stanja kod korisnika imaju prenaglašene facijalne crte nalik crtanim likovima, oblih ivica, ženskog pola i jarkih boja. Roboti koji imaju realistične osobine, manje naglašene facijalne crte i tamne dominantne boje su asocirani sa negativnim ponašanjima. Autori predlažu da roboti za decu ne treba da budu nalik čoveku, već je izgled koji je mešavina ljudskog i karakteristika mašine deci najprivlačnija.

U odnosu na polne razlike, pokazano je da ispitanici ženskog pola imaju viši skor na skali koja meri nepoverenje prema dostignućima robotike (Fong i Nourkhbash, 2003). Takođe, starost i stepen stručne spreme određuju stepen pozitivnih osećanja koja ispitanici ispoljavaju prema primeni robota. Stariji ispitanici pokazuju manje pozitivan stav prema robotima. Najmlađi ispitanici i ispitanici viših stepena stručne spreme imaju najpozitivniji stav prema korišćenju robota (Fong i Nourkhbash, 2003). U ispitivanju gde je od ispitanika traženo da doniraju novac robotu pokazalo se da su muškarci bili skloniji donaciji novca robotu koji je ženskog pola, dok žene nisu pokazale nikakvu preferenciju u tom smislu. Takođe, roboti suprotnog pola su generalno procenjivani kao kompetentniji, pouzdaniji i privlačniji. Ovaj efekat je izraženiji u slučaju muških ispitanika u odnosu na ženske ispitanike (Siegel, 2009). Pitanje koje se postavlja u ovom istraživanju u odnosu na pol je da li kod dece postoje polne razlike u preferenciji robota koji se razlikuju po fizičkim karakteristikama, kao što su crte lica, kompaktnost, oblina ivica itd, kao i u pripisivanju pola robotu. Uzimajući u obzir nalaze prethodnih istraživanja, može se pretpostaviti da će dečaci biti skloniji polnoj tipizaciji, dok će devojčice podjednako pripisivati kako ženski, tako i muški pol robotu. Međutim, može se očekivati da će se robotu nešto češće atribuirati ženski pol, s obzirom da je pokazano da su roboti ženskog pola procenjivani 
kao prijatniji.

Mnoštvo istraživanja pokazuje da su svojstva kao što su nijansa, bistrina i saturacija, informacije o bojama koje imaju potencijal da utiču na percepciju, fiziološke, emocionalne ili bihejvioralne reakcije (Valdez i Mehrabian, 1994). Smatra se da boje veće talasne dužine (npr., žuta i crvena) deluju više uznemirujuće nego što je to slučaj kod boja kraćih talasnih dužina, na primer plava i zelena (Jacobs i Hystmyer, 1974 prema Cyr i sar, 2009, Goldberg i Kotval, 1999; Marcus i Gould, 2000). Plava boja je asocirana sa blagostanjem, poverenjem i sigurnošću, i spada među omiljene boje (Carte i Russell, 2003; Meyers-Levy i Peracchio, 1995). U svetu marketinga poznato je da boja utiče na stav potrošača prema određenom proizvodu ili brendu.

Brojni faktori utiču na preferenciju boja, uključujući pol ispitanika, koji ima uticaj na jačinu preferencije i konzistentnost preferencije (Guilford \& Smith 1959 prema Cyr i sar, 2009). Takođe, velik broj crta ličnosti utiče na prefereciju boja ispitanika, na primer ekstravertima više odgovaraju tople boje, dok introverti biraju hladne boje (Benson et al. 2000). Jedno od pitanja koja se postavljaju u ovom istraživanju je i kako će deca odabrati boje koje najviše pristaju robotu? Da li su deca osnovnoškolskog uzrasta već usvojila tumačenja koja se odnose na pripisivanje značenja bojama? Ukoliko je odgovor na ovo pitanje potvrdan, na osnovu nalaza prethodnih istraživanja može se očekivati da će deca prvenstveno birati boje koje su generalno asocirane sa sigurnošću, poverenjem, snagom, dostojanstvenošću i pozitivnim osećanjima, a to su određene nijanse plavog i zelenog.

Dosadašnja istraživanja nisu ispitivala stav roditelja prema korišćenju robota čija deca su potencijalni korisnici robota. Očekuju se razlike u stavovima očeva i majki, koji se mogu objasniti uz pomoć nekoliko faktora: 1) majke su više uključene u brigu o deci, i stoga mogu da budu skeptičnije u vezi korišćenja novih metoda u edukaciji dece; 2) moguće je da su ispitanici ženskog pola generalno manje zainteresovani za razvoj robotike, te su kritičnije (ili čak zbog nedovoljne informisanosti) manje kritične u svom stavu prema primeni robota. Takođe, očekuje se da će stručna sprema roditelja biti faktor koji utiče na stav prema robotu, tako da će obrazovaniji roditelji imati pozitivniji stav. 


\section{CILJEVI ISTRAŽIVANJA}

Prvi cilj istraživanja je da se odgovori na pitanje da li postoji razlika u preferenciji različitih modela robota kod dece, kao i da li postoji razlika u zastupljenosti različitih boja kojima deca boje modele?

Drugi cilj istraživanja je da se odgovori na pitanje da li postoje polne razlike u preferenciji različitih modela robota kod dece, kao i u pripisivanju pola robotu? Očekuje se da će deca češće birati modele koji imaju blage i dobroćudne crte. Takođe, očekuje se da će boje koje će deca koristiti za bojenje modela biti pre svega boje koje su asocirane sa pozitivnim osećanjima i poverenjem, a to su pre svega određene nijanse plave boje i zelene.

Treći cilj istraživanja je da se odgovori na pitanje da li postoji razlika u stavu prema robotu kod roditelja u zavisnosti od njihove stručne spreme, pola i starosti?

\section{METOD}

\section{Uzorak}

U prvom delu istraživanja je učestvovalo 196 učenika prvih razreda iz sedam osnovnih škola sa teritorije Južnobačkog okruga. podaci o polu su bili dostupni za 155 učenika. Uzorak je relativno ujednačen po polu. U drugom delu istraživanja je učestvovalo 130 roditelja (od toga 93 majki i 37 očeva).

\section{Procedura}

Po jedan školski čas je bio namenjen istraživanju. Nakon što je ispitivač izložio kratku priču o Pametnom Pronalazaču koji želi da napravi robota koji će pomagati deci (kratka priča koja je predstavljena deci, kao i zadata instrukcija nalaze se u prilogu br. 1.), deca dobijaju instrukciju da izaberu jednu od ukupno pet ponudjenih crno-belih skica koje će zatim obojiti u boje koje smatraju najprivlačnijim. Skice koje su prezentovane deci izabrane su od strane tima istraživača na osnovu pilot istraživanja koje je pokazalo koje su to crte crtanih figura koje su deci najprivlačnije (crno-beli crteži robota se nalaze u prilogu br. 2). Nakon što je grupno zadata instrukcija, zadatak dece je bio da oboje crno-belu skicu robota koju su odabrali. Dok su deca radila na zadatku ispitivači su ukratko porazgovarali o liku na odabranom crtežu, kao i o ostalim likovima robota sa svakim detetom ponaosob. Neka od pitanja koja su postavljana deci su otvorenog tipa (npr., „Kakav je ovaj robot“), neka pitanja 
su bila zatvorenog tipa (pitanje o polu robota), i nekoliko pitanja je bilo Likertovog tipa, gde su deca odgovarala o potencijalnim osobinama robota na skali od jedan do tri. Elaboracije deteta su takodje zapisivane, gde je to bilo moguće (Pitanja koja su postavljana deci se nalaze u prilogu br. 3).

U drugoj fazi istraživanja roditelji su popunjavali upitnik koji je sastavljen za potrebe ovog istraživanja. Upitnik se sastoji iz 39 tvrdnji Likertovog tipa, koji se odnose na stav roditelja prema robotu. Ove tvrdnje obuhvataju stav roditelja prema robotu kao pomagaču, kolegi ili savetodavcu. Nekoliko pitanja se odnosi na roditeljski stav prema tome da li se robot može smatrati podrškom i da li je interakicja sa njim moguća. Druga grupa pitanja se odnose na stav roditelja prema korišćenju robota uopšte. Treća grupa pitanja ispituje koliko su roditelji samopouzdani po pitanju rukovanja robotom, dok je četvrta gupa pitanja usmerena na roditeljski stav da li bi robot bio efikasan u radu sa decom, i da li smatraju da postoji opasnost povređivanja deteta od strane robota, kao i pitanje predvidljivosti ponašanja robota. Takođe, nekoliko pitanja se odnosi na mišljenje roditelja o tome da li postoji opasnost da dete pokvari robota.

\section{Varijable}

$\mathrm{U}$ istraživačkom smislu nezavisne varijable su pol deteta, pol roditelja, stručna sprema roditelja, i starost roditelja.

Zavisne varijable su detetov izbor crno-belog modela robota, detetovi odgovori na postavljena pitanja o karakteristikama robota, kao i boja koju koriste za bojenje robota. Takođe, zavisna varijabla je skor roditelja na upitniku o stavu prema robotima.

\section{REZULTATI I DISKUSIJA}

Prvi deo istraživanja: deca

Rezultati $\chi^{2}$ testa $\left(\chi^{2}=30.327, p=.000\right)$ pokazuju da deca smatraju različite modele različito privlačnim. Najpopularniji su model b i model e, dok je najmanje biran model d (tabela br. 1). Model b i model e predstavljaju robote veoma oblih ivica (prilog br. 2). Ovi roboti deluju kompaktno i zdepasto, što deca verovatno tumače kao 
dobronamernost. Oba modela su animalnog izgleda, imaju okruglu glavu i podsećaju na miša, odnosno medveda. Roboti koji su manje birani imaju nešto hominidnije crte, svi imaju dugačke ruke koje po proporcijama podsećaju na ljudske ruke, a model c ima čak i noge. Može se pretpostaviti da je model c biran relativno često iz razloga što je ovaj model interesantniji u odnosu na ostale modele-pored robota, na crtežu se nalazi i konj. Ovi rezultati su u skladu sa nalazima ranijih istraživanja (Woods i sar, 2004), prema kojima roboti koji izazivaju pozitivna emocionalna stanja, i koji su iz tog razloga preferirani, imaju prenaglašene facijalne crte nalik crtanim likovima, i više su animalnog nego humanoidnog izgleda. $\mathrm{Na}$ osnovu preferencija može se zaključiti da se deci pre svega sviđaju likovi koji su oblih, blagih crta, sa femininim odlikama, dok su modeli koji imaju proporcije sličnije proporcijama ljudskog tela manje dopadljive.

Polne razlike u biranju modela su takođe uočljive $\left(\chi^{2}=15.849, \mathrm{p}=.003\right)$. Najuočljivije su polne razlike kod modela d i e: devojčice češće biraju model e u odnosu na dečake, dok dečaci češće biraju model d, iako je ovaj model uopšteno biran najmanje frekventno (tabela br. 1).

\begin{tabular}{lccccccc}
\hline Kog robota su izabrali & $\mathbf{a}$ & $\mathbf{b}$ & $\mathbf{c}$ & $\mathbf{d}$ & $\mathbf{e}$ & Total \\
\hline Pol deteta & Muški & 13 & 21 & 18 & 11 & 12 & 75 \\
& & $17.3 \%$ & $28.0 \%$ & $24.0 \%$ & $14.7 \%$ & $16.0 \%$ & \\
& \multirow{2}{*}{ Ženski } & 10 & 28 & 14 & 1 & 27 & 80 \\
& $12.5 \%$ & $35.0 \%$ & $17.5 \%$ & $1.2 \%$ & $33.8 \%$ & \\
\multirow{2}{*}{ Total } & 23 & 49 & 32 & 12 & 39 & 155 \\
& $14.8 \%$ & $31.6 \%$ & $20.6 \%$ & $7.7 \%$ & $25.2 \%$ & \\
\hline
\end{tabular}

Tabela 1. Frekvence i procenti izbora pojedinih modela u zavisnosti od pola deteta

Dečaci najčešće biraju model b i model c. Veća preferencija modela c kod dečaka može se objasniti time što model c deluje kao muški lik koji jaše konja. Interesantno je da dečaci većinski pripisuju muški pol robotu dok je za devojčice $42,5 \%$ muški i $57,5 \%$ ženski pol (tabela br. 2), što potvrđuje da je polno tipiziranje 
veće kod dečaka nego kod devojčica. Roboti kojima je najčešće pripisivan muški pol, su modeli a i c, dok su modeli b i e podjednako često tumačeni i kao muški i ženski (tabela br. 3). I ovaj rezultat je u skladu sa nalazima ranijih istraživanja (e.g. Woods i sar, 2004), koja pokazuju da se robotima koji se procenjuju kao najprijatniji pripisuje pre svega ženski pol, ili oba pola podjednako, dok isključivo pripisivanje robotu muškog pola ukazuje na to da ispitanici robota doživljavaju kao potencionalno negativnog.

\begin{tabular}{lcccc}
\hline & \multicolumn{4}{c|}{ Kog je pola robot } \\
\hline \multirow{2}{*}{ Pol deteta } & Muški & 67 & Ženski & Total \\
& & $89,3 \%$ & $10,7 \%$ & 75 \\
& Ženski & 34 & 46 & \\
& & $42,5 \%$ & $57,5 \%$ & \\
& Total & 101 & 54 & 155 \\
& & $65,2 \%$ & $34,8 \%$ & \\
\hline
\end{tabular}

Tabela br. 2. Pripisivanje pola robotu u zavisnosti od pola deteta

\begin{tabular}{cccccccc}
\hline & \multicolumn{6}{c}{ Kog robota su izabrali } & \multicolumn{2}{c}{ Total } \\
\hline & Muški & $\mathrm{a}$ & $\mathrm{b}$ & $\mathrm{c}$ & $\mathrm{d}$ & $\mathrm{e}$ & \\
& 26 & 33 & 31 & 10 & 28 & 128 \\
& $20.3 \%$ & $25.8 \%$ & $24.2 \%$ & $7.8 \%$ & $21.9 \%$ & $100.0 \%$ \\
$\begin{array}{c}\text { Kog pola je } \\
\text { robot }\end{array}$ & Ženski & 6 & 23 & 9 & 4 & 26 & 68 \\
& & $8.8 \%$ & $33.8 \%$ & $13.2 \%$ & $5.9 \%$ & $38.2 \%$ & $100.0 \%$ \\
& Total & 32 & 56 & 40 & 14 & 54 & 196 \\
& & $16.3 \%$ & $28.6 \%$ & $20.4 \%$ & $7.1 \%$ & $27.6 \%$ & $100.0 \%$ \\
\hline
\end{tabular}

Tabela br. 3. Procenat i frekvenca pripisivanja muškog $i$ ženskog pola modelima robota

U odnosu na boje kojima su deca obojili modele, dominantna boja je bila plava, kao i razne kombinacije koje obuhvataju plavu boju. Čak 52.7 \% dece koristi 
plavu boju kao dominantnu. Ovaj rezultat je u skladu sa teorijama o značenju boja, prema kojoj je plava boja umirujuća, otmena i ozbiljna (e.g. Hevner, 1935). Plava je boja koja se veoma često asocira sa poverenjem i osećanjem sigurnosti, kao i staloženošću. Zanimljivo je primetiti, da deca već na ranom uzrastu asociraju boje na način na koji to čine odrasli, većinom bojeći skicu robota plavom bojom, koja je u medijima asocirana sa modernom tehnologijom. Ovaj rezultat bi indirektno mogao govoriti u prilog podložnosti dece uticajima medija.

\section{Drugi deo istraživanja: roditelji}

$\mathrm{Na}$ osnovu rezultata analize odgovora roditelja može se zaključiti da $\mathrm{u}$ mišljenju roditelja prevladava više pozitivan nego negativan stav prema robotu kao pomagaču, kolegi ili savetodavcu, i skloni su mišljenju da se robot moze posmatrati podrškom, te da je interakicja sa njim moguća- najčešće biran stepen slaganja na upitniku je opcija 3 (neutralno: nisam siguran) i 4 (delimično se slažem). Ovaj rezultat je takođe u skladu sa nalazima ranijih istraživanja (npr., Heerink i sar, 2009) prema kojima ispitanici imaju pre svega pozitivan stav prema primeni robota, i skloni su da stupe u interakciju sa robotom (Nass i Moon, 2000). Rezultati ovog istraživanja potvrđuju ranije nalaze da su ljudi genralno skloni pripisivanju intencionalnosti neživim entitetima, kao i atribuisanju pola i socijalnih uloga robotima. Rezultati ovog istraživanja potvrđuju da su ispitanici generalno skloni antropomorfizaciji robota time što im pripisuju emotivne i cognitivne procese, što potvrđuje značajnu ulogu principa racionalne akcije u diskriminaciji agenata (npr., Duffy, 2003; Csibra i Gergely, 2007).

Rezultati pokazuju da su majke sklonije davanju ekstremnih odgovora na upitniku (11,62\% zena daje ekstremne odgovore) o stavu prema robotu u odnosu na očeve (diagram br. 1). Nakon detaljnije analize autlajera može se zaključiti da ovi ekstremni odgovori nisu rezultat nasumičnog trenda odgovaranja, već zaista reflektuju pre svega izrazito kritičan stav prema korišćenju robota $(9,3 \%$ majki ima stil odgovaranja ovog tipa), ili izrazito pozitivan stav (2,32\% majki odgovara na ovaj način). 


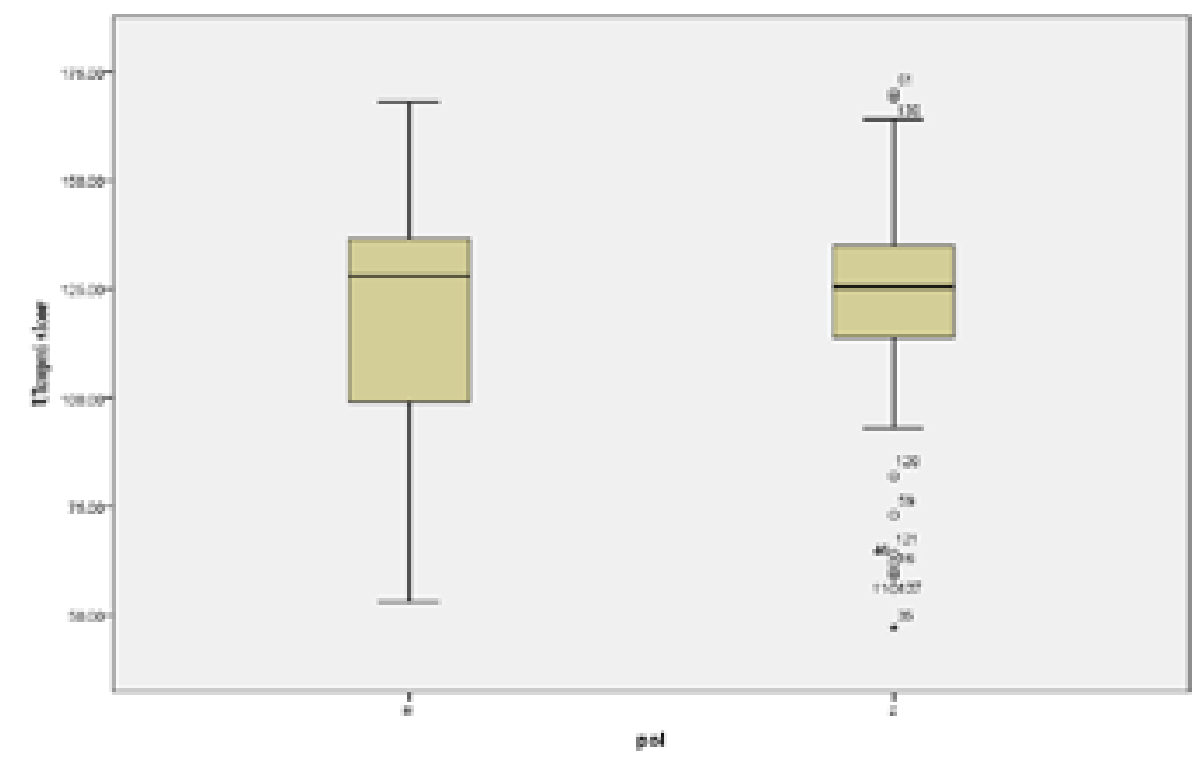

Diagram br. 1. Prikaz varijanse ukupnog skora muških $i$ ženskih ispitanika

Dalja analiza rezultata je vršena bez uzimanja u obzir pomenutih ekstremnih slučajeva. Rezultati univarijatne ANOVE, gde je zavisna varijabla ukupni skor ispitanika na upitniku, dok su faktori pol i stručna sprema ispitanika, pokazuju značajan glavni efekat pola $\left(\mathrm{F}(1,114)=8,722, \mathrm{p}=.004, \eta^{2}=.075\right)$, kao i značajnu interakciju između pola i stručne spreme roditelja $\left(F(3,114)=3,401, p=.020, \eta^{2}=\right.$ .087). Roditelji II stepena stručne spreme su najmanje kritični prema upotrebi robota, dok se najnegativniji stav može uočiti kod ispitanika VII-2 i VIII stepena stručne spreme.

Dobijene polne razlike nisu u skladu sa pretpostavkom prema kojoj će majke imati kritičniji stav prema primeni robota. Suprotno očekivanjima, majke deluju manje skeptičnim (grafikon br. 1). Majke imaju trend odgovaranja koji je nešto pozitivniji od očeva, međutim ova razlika je statistički značajna jedino u slučaju ispitanika VIII stepena stručne spreme. U tim slučajevima majke su sklone pozitivnijem stavu, dok su očevi izrazili izrazito negativan stav na upitniku o korišćenju robota u edukativne svrhe (grafikon br. 1). I majke i očevi sa nižim stepenom obrazovanja iskazuju podjednako pozitivan stav na upitniku. Može se pretpostaviti da su roditelji nižih 
stepena obrazovanja generalno manje kritični u odnosu na potencijalne inovacije. Sa druge strane, roditelji viših stepena obrazovanja imaju nešto kritičniji stav prema korišćenju robota, iako i dalje imaju više pozitivan nego negativan stav. Kod ispitanika VIII stepena stručne spreme uočljiva je izuzetno velika razlika u trendu odgovaranja u zavisnosti od pola: očevi su izuzetno kritični- što se može objasniti generalno većim interesovanjem očeva za oblasti kao što su robotika i razvijanje veštačke inteligencije, te su stoga i upoznatiji sa mogućnostima i ograničenjima ove naučne discipline. Međutim, može se pretpostaviti da majke VIII stepena stručne spreme imaju uopšteno pozitivan stav prema inovacijama, ali nisu u istoj meri upoznate sa mogućnostima i ograničenjima primene robota, te su stoga izrazito nekritične u svom stavu prema korišćenju robota u radu sa ljudima. U budućim istraživanjima bilo bi poželjno povećati broj roditelja sa VIII stepenom stručne spreme, s obzirom da je broj roditelja sa magistraturom i doktoratom bio izrazito mali u ovom istraživanju.

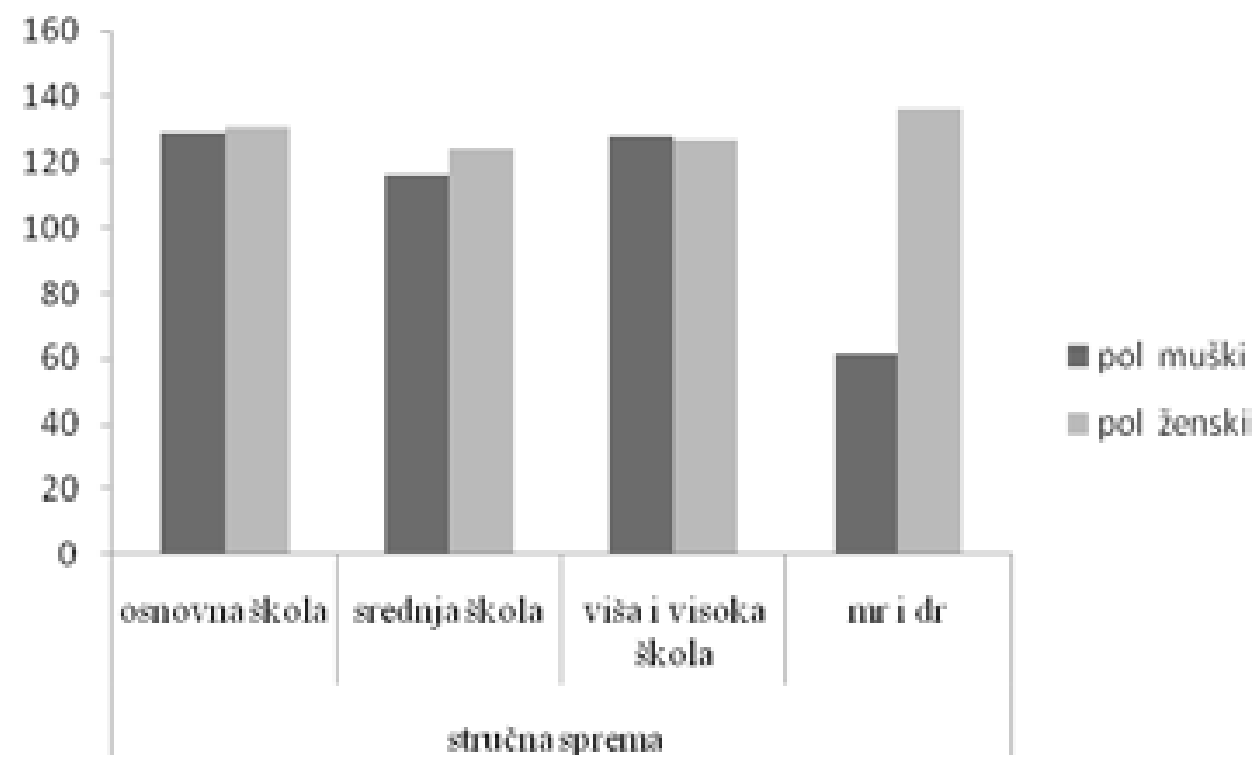

Grafikon br. 1. Skorovi ispitanika na upitniku stava prema robotu u zavisnosti od stručne spreme i pola 


\section{ZAKLJUČCI}

$\mathrm{Na}$ osnovu rezultata istraživanja može se zaključiti da deca smatraju različite modele različito privlačnim. Dva modela se ističu kao najčešće birana, a to su modeli animalnog izgleda, koji imaju prenaglašene facijalne crte nalik crtanim likovima, deluju kompaktno i zdepasto. Preferencija modela robota koji su oblih ivica i deluju dobronamerno je u skladu sa očekivanjima.

Takođe, uočene su polne razlike u preferenciji modela i pripisivanju pola robotima: dečaci većinski pripisuju muški pol robotu dok devojčice podjednako pripisuju i muški i ženski pol robotu, što potvrđuje hipotezu da je polno tipiziranje veće kod dečaka nego kod devojčica. Robotima koji se procenjuju kao najprijatniji pripisuje pre svega ženski pol, ili oba pola podjednako, dok isključivo pripisivanje robotu muškog pola ukazuje na to da ispitanici robota doživljavaju kao potencionalno negativnog.

U odnosu na boje kojima su deca obojili modele, dominantna boja je bila plava, kao i razne kombinacije koje obuhvataju plavu boju. Ovaj rezultat indirektno govori u prilog podložnosti dece uticajima medija.

$\mathrm{Na}$ osnovu rezultata analize odgovora roditelja može se zaključiti da u mišljenju roditelja prevladava više pozitivan nego negativan stav prema robotu kao pomagaču. Rezultati pokazuju da su majke sklonije davanju ekstremnih odgovora na upitniku o stavu prema robotu u odnosu na očeve.

Dobijene polne razlike nisu u skladu sa pretpostavkom prema kojoj majke imaju kritičniji stav prema primeni robota. Suprotno očekivanjima, majke su manje skeptične u odnosu na očeve. Majke imaju trend odgovaranja koji je nešto pozitivniji od očeva, međutim ova razlika je statistički značajna jedino u slučaju ispitanika VIII stepena stručne spreme - majke su sklone pozitivnijem stavu, dok su očevi izrazili izrazito negativan stav na upitniku o korišćenju robota. Međutim, rezultat koji se odnosi na stručnu spremu roditelja neophodno je uzeti sa rezervom, s obzirom da je zastupljenost roditelja VIII stepena stručne spreme izrazito niska, te se predlaže da se u budućim istraživanjima poveća broj roditelja sa magistraturom i doktoratom.

\section{LITERATURA}


Benson, L.M., Bruce, M. \& Hogg, M.K. (2000) An investigation into the impact of consumers' personality traits on their colour preference, In B. Wierenga, A. Smidts and G. Antonides (Eds), EMAC Conference proceedings, 29, (Book of abstracts, p. 118), Rotterdam: Erasmus University.

Bumby,K., \& Dautenhahn , K. (1999), Investigating children's attitudes towards robots: A case study, Proc. CT99, The ThirdInternational Cognitive Technology Conference, (pp. 391-410), August, San Francisco, USA.

Carte, T.A., \& Russell, C.J. (2003). In pursuit of moderation: nine common errors and their solutions. MIS Quarterly 27 (3), 479-501.

Csibra, G, \& Gergely, G. (2007) 'Obsessed with goals': Functions and mechanisms of teleological interpretation of actions in humans. Acta Psychologica, 124(1), 60-78.

Cyr, D., Head, M., Larios, H., \& Pan, B. (2009). Exploring human images in website design across cultures: a multi-method approach. MIS Quarterly 33 (3), 539-566.

Fong, T., \& Nourbakhsh, I. (2003). Socially interactive robots. Robotics and Autonomous Systems, 42: 139-141.

Gitlin, L.N. (1995). Why older people accept or reject assistive technology. Generations, Journal of

Goldberg, J.H., Kotval, X.P., (1999). Computer interface evaluation using eye movements: methods and constructs. International Journal of Industrial Ergonomics 24, 631-645.

Marcus, A., \& Gould, E.W. (2000). Cultural dimensions and global web user interface design. Interactions 7 (4), 33-46.

Meyers-Levy, J., \& Peracchio, A. (1995). Understanding the effects of colour: how the correspondence between available and required resources affects attitudes. Journal of Consumer Research 22 (2), 121-138.

Siegel, M., Breazeal, C., \& Norton, M.I., (2009). Persuasive Robotics: The Influence of Robot Gender on Human Behavior, The 2009 IEEE/RSJ International Conference on Intelligent Robots and Systems, October 11-15, 2009 St. Louis, USA.

Valdez, P., \& Mehrabian, A. (1994). Effects of color on emotions. Journal of Experimental Psychology 123, 394-409.

Woods, S., Dautenhahn, K., \& Schulz, J.(2004). The Design Space of Robots: 
Investigating Children's Views, Robot and Human Interactive Communication, 2004. ROMAN 2004. 13th IEEE International Workshop (Book of abstracts pp. 47-52), 22 24 Oktober, Sch. of Comput. Sci., Hertfordshire University, Hatfield, UK.

Ivan Jerković, Agota Major \& Marina Oros

Department of Psychology, Faculty of Philosophy, University of Novi Sad

\title{
ASSISTIVE ROBOTS WORKING WITH CHILDREN - SEEN BY CHILDREN AND PARENTS
}

\begin{abstract}
The study presented in this paper aimed to answer three main questions - the difference in children's preference of robot appearance and colour; gender differences in children's preference of different models of robots and in the attribution of gender to the robot; the difference in attitudes towards robots of parents depending on gender, age and socioeconomic status. The sample consists of first grade children and their parents from seven primary schools. Results show that children prefer models of robots which are animal-like, with overstressed cartoon-like facial features and are compact and stocky. Gender differences in the model preference and gender attributed to the robot were found. Dominant colour that children coloured the robot pictures was blue. Parents have more positive than negative attitude towards the assistive robots.
\end{abstract}

Key words: children's preference of robots, gender, age, attitudes of parents towards assistive robots 


\section{PRILOZI}

\section{Prilog br. 1}

„Jedan mnogo pametan čika pronalazač želi da napravi robota za decu. Ovaj robot treba da bude deci prijatelj i učitelj, treba da se sviđa deci, da im pomaže, pa je naš pametni čika pronalazač mislio da je najbolje da pita decu kako robot treba da izgleda.

Ovi crteži su primeri nekoliko robota... Dobro ih pogledate i odaberite koji vam se najviše dopada. Kada odlučite koji vam se najviše sviža, dobićete taj crtez i zadatak je da ga obojite u one boje koje bi mu najbolje pristajale."

Dati deci crtez i ponoviti instrukciju: Vaš zadatak je da obojite taj crtež u one boje koje bi mu najbolje pristajale". 


\section{Prilog br. 2}

Model A

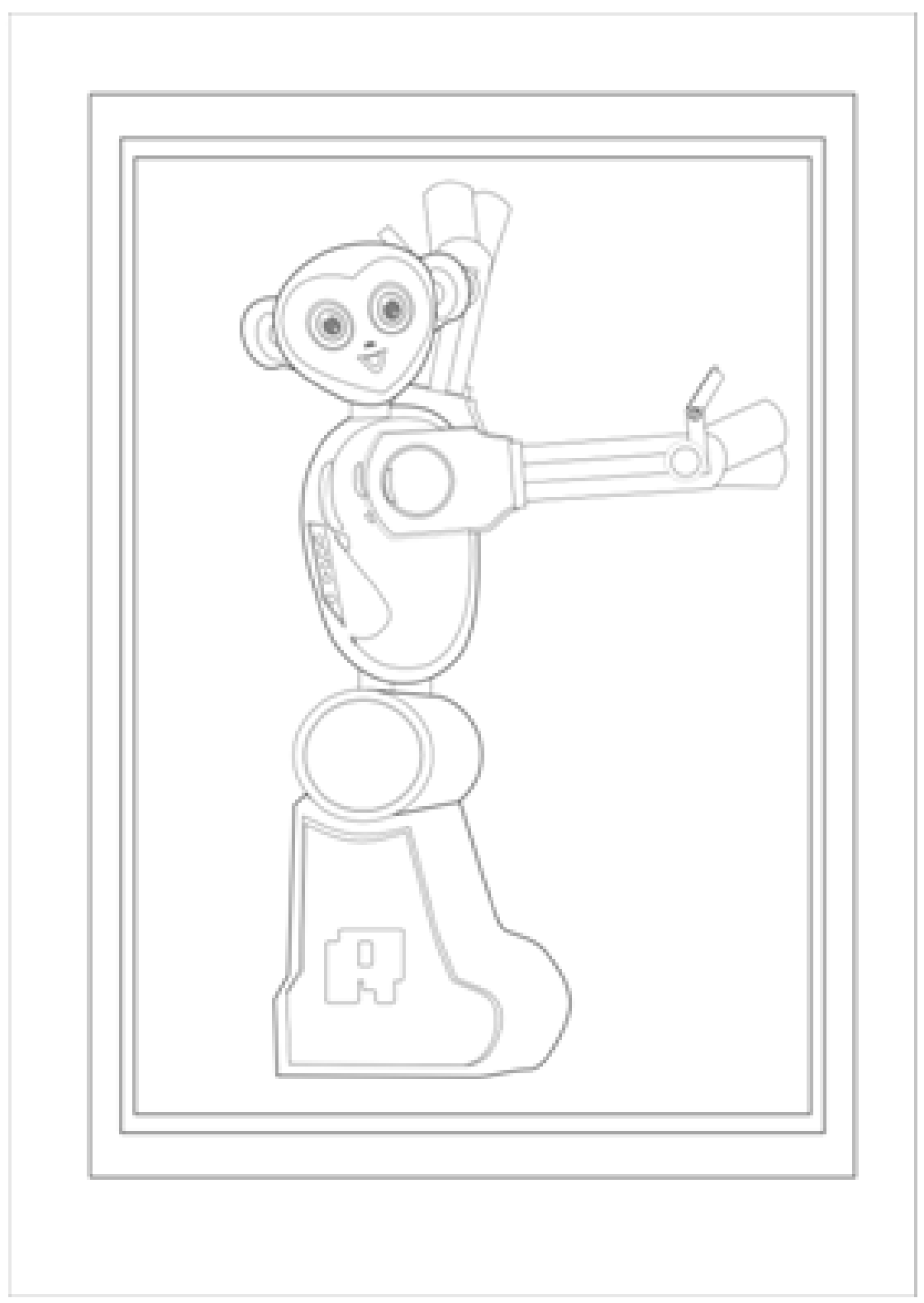


Model B

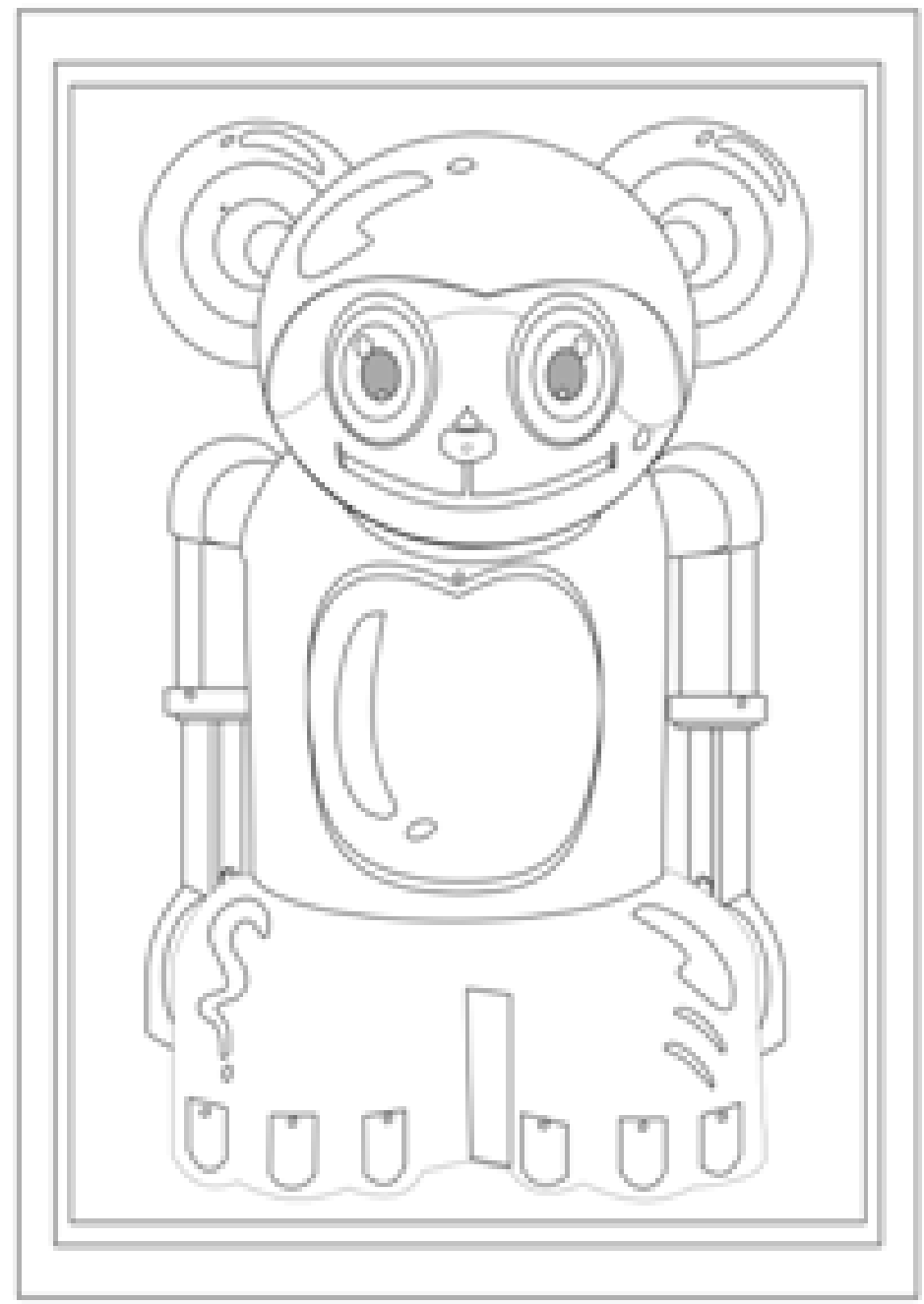


Model C

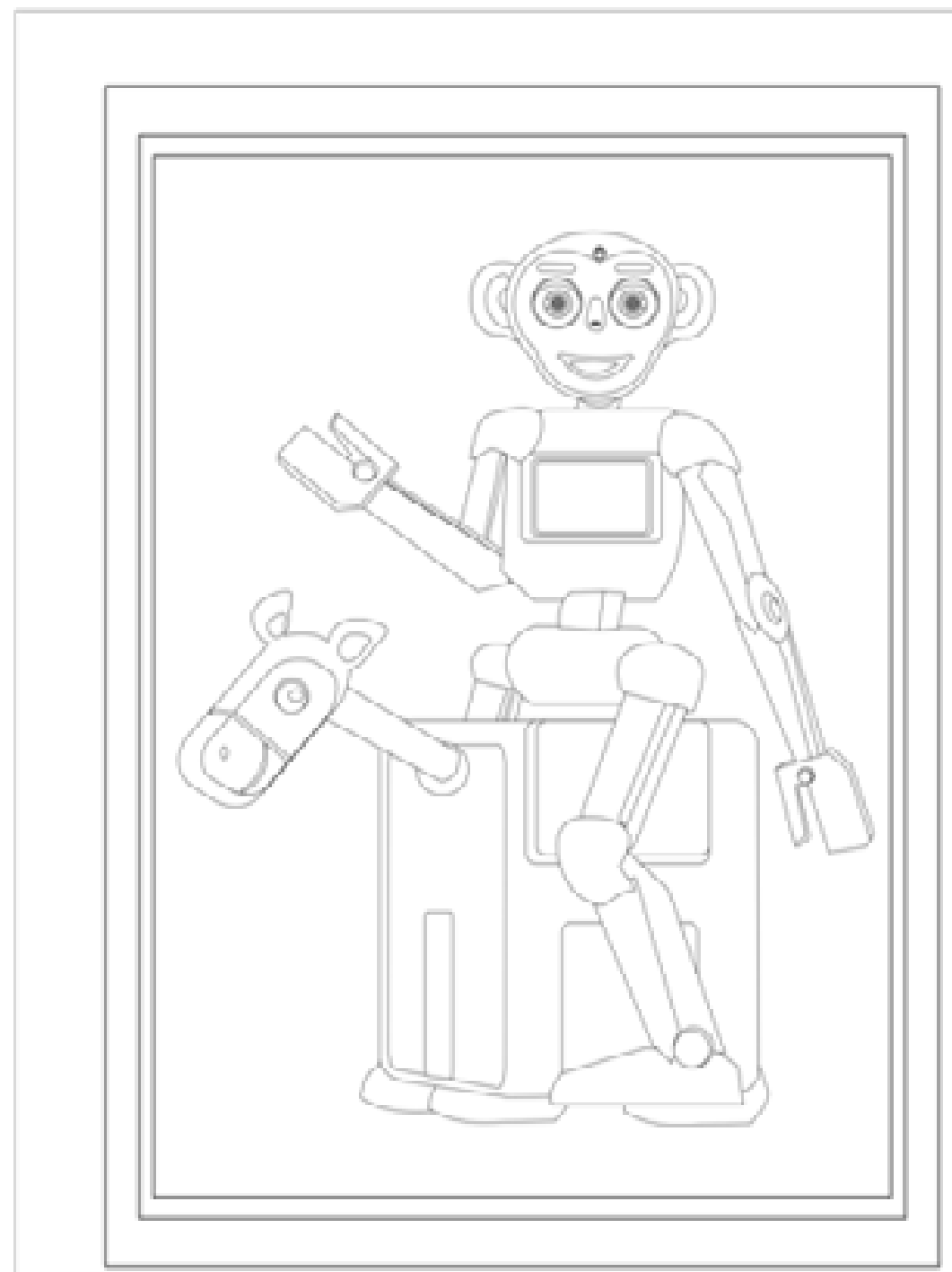


Model D

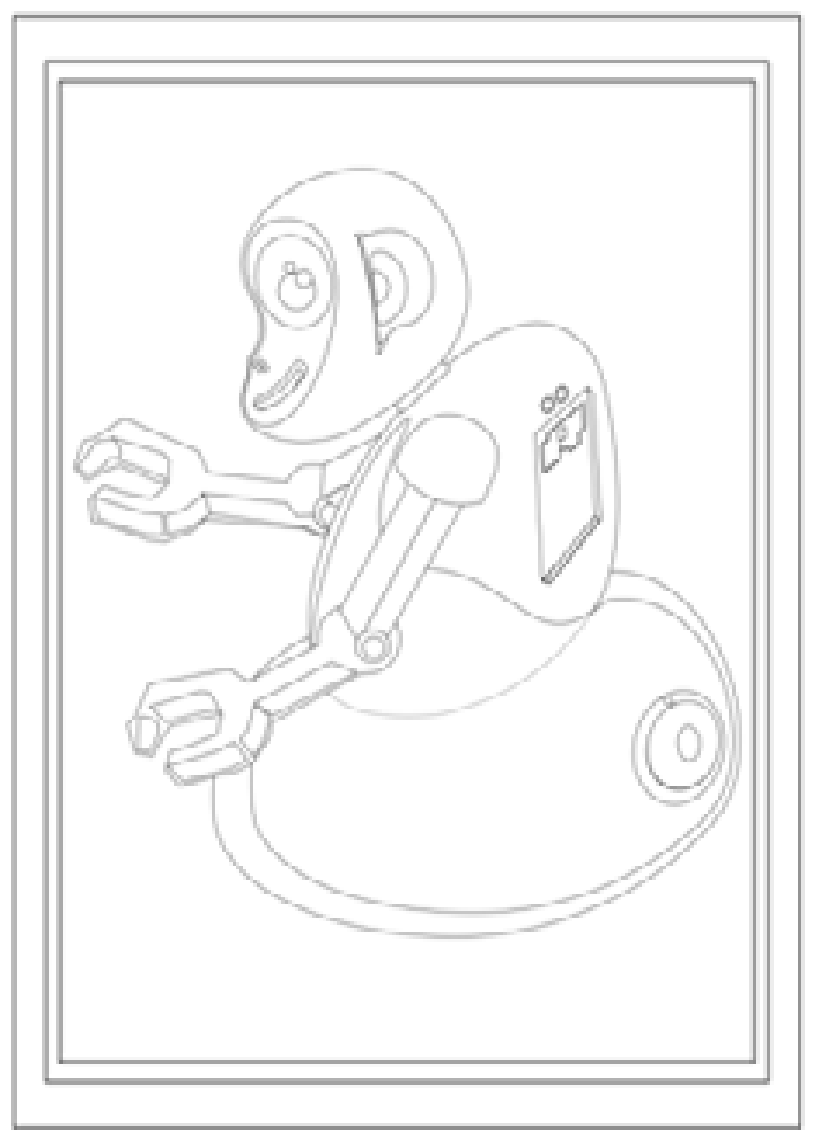


Model E

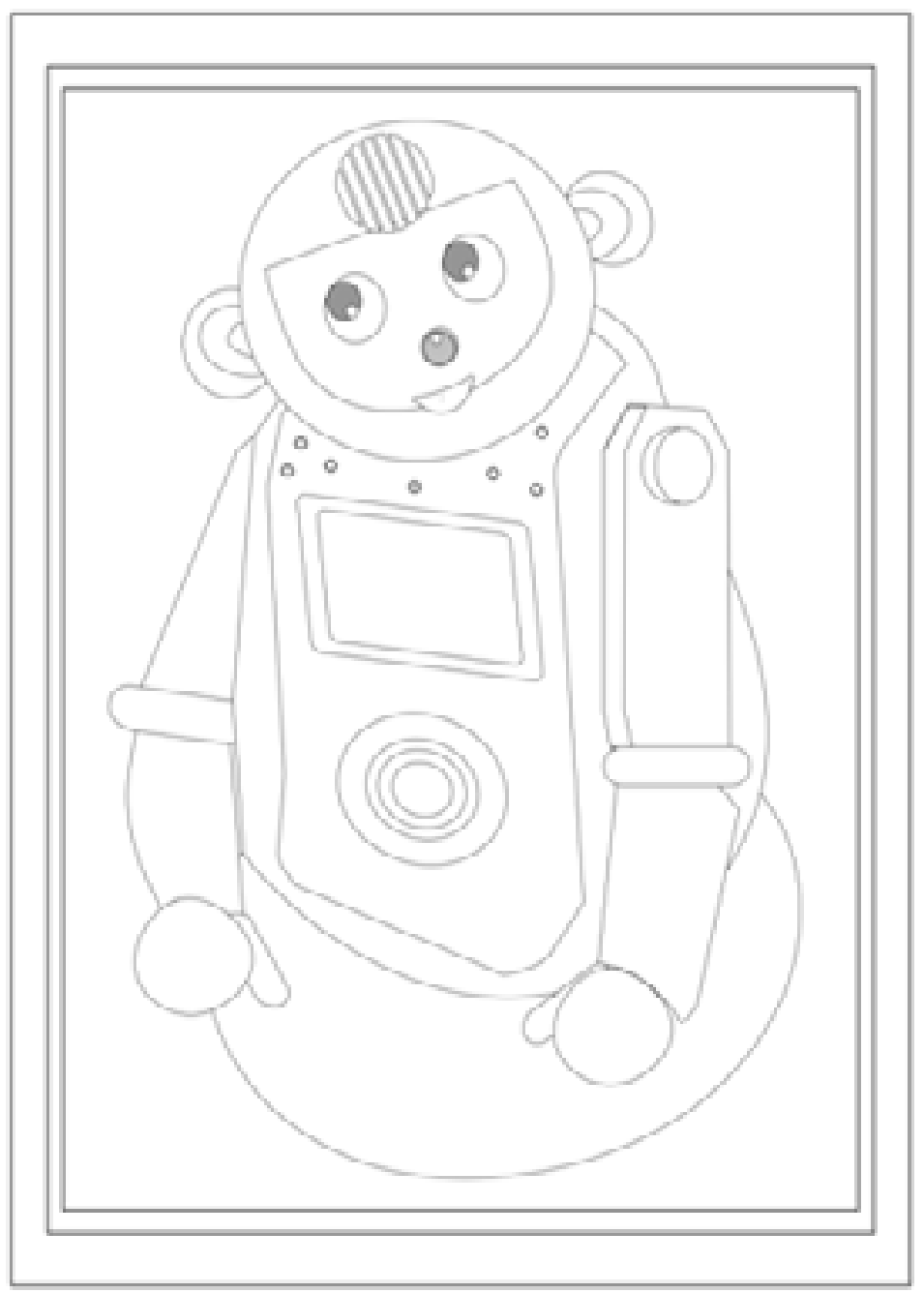




\section{Prilog br. 3.}

Inicijali deteta

Ispitivač

Robot koji je izabran

Kakav je ovaj robot?

Da li je ovaj robot: zaokružite zapišite eventualne elaboracije deteta

\begin{tabular}{|c|l|c|c|c|l|}
\hline 1. & Veseo & da & ne & ne znam & \\
\hline 2. & Tužan & da & ne & ne znam & \\
\hline 3. & Ljut & da & ne & ne znam & \\
\hline 4. & Strog & da & ne & ne znam & \\
\hline 5. & Pemetan & da & ne & ne znam & \\
\hline 6. & Blag & da & ne & ne znam & \\
\hline 7. & Poslušan & da & ne & ne znam & \\
\hline 8. & Voli da se igra & da & ne & ne znam & \\
\hline 9. & Voli decu & da & ne & ne znam & \\
\hline 10. & Plašljiv & da & ne & ne znam & \\
\hline 11. & Bučan & da & ne & ne znam & \\
\hline 12. & Bezobrazan & da & ne & ne znam & \\
\hline
\end{tabular}

Da li je ovaj robot muško ili žensko?

Kako bi se zvao tvoj robot? 


\section{Prilog br. 4}

\section{Upitnik za roditelje o stavu prema robotima}

Poštovani,

Pred Vama se nalazi kratak upitnik čijim ispunjavanjem ćete dati doprinos naučnom projektu koji za cilj ima razvoj robota kao sredstva pomoći u terapiji dece sa teškoćama u razvoju. Zanima nas Vaš stav o mogućnosti korišćenja robota u radu sa decom. Hvala na saradnji!

Pol: $\quad$ M $\quad \check{Z}$

Starost:

Stepen stručne spreme: a) osnovna škola

b) srednja škola

c) viša ili visoka

d) magisterijum ili doktorat

Zaokružite stepen slaganja sa navedenom tvrdnjom: 1 - uopšte se ne slažem

2 - delimično se ne slažem

3 - nisam siguran

4 - delimično se slažem

5 - potpuno se slažem

\begin{tabular}{|c|l|c|c|c|c|c|}
\hline 1. & Verovao bih robotu kada bi mi dao neki savet. & 1 & 2 & 3 & 4 & 5 \\
\hline 2. & Mislim da je korišćenje robota dobra ideja. & 1 & 2 & 3 & 4 & 5 \\
\hline 3. & Bojim se da bih nešto pogrešio ili polomio u toku korišćenja robota. & 1 & 2 & 3 & 4 & 5 \\
\hline 4. & Da imam robota mnogi ljudi bi time bili oduševljeni. & 1 & 2 & 3 & 4 & 5 \\
\hline 5. & Sledio bih savet robota. & 1 & 2 & 3 & 4 & 5 \\
\hline 6. & Roboti bi bili dobre kolege. & 1 & 2 & 3 & 4 & 5 \\
\hline 7. & Bojim se da bih zbog robota mogao izgubiti posao. & 1 & 2 & 3 & 4 & 5 \\
\hline 8. & Mogao bih govorom kontrolisati robota. & 1 & 2 & 3 & 4 & 5 \\
\hline 9. & Mislim da je lako koristiti robota. & 1 & 2 & 3 & 4 & 5 \\
\hline 10. & Sviđalo bi mi se prisustvo robota. & 1 & 2 & 3 & 4 & 5 \\
\hline 11. & Mogao bih rešavati radne zadatke zajedno sa robotom. & 1 & 2 & 3 & 4 & 5 \\
\hline 12. & Osećao bih se ugroženim od strane robota. & 1 & 2 & 3 & 4 & 5 \\
\hline 13. & Robot bi mi bio od koristi. & 1 & 2 & 3 & 4 & 5 \\
\hline 14. & Robot mi mi mogao pomoći u različitim zadacima i obavezama. & 1 & 2 & 3 & 4 & 5 \\
\hline
\end{tabular}




\begin{tabular}{|c|c|c|c|c|c|c|}
\hline 15. & Robot bi mi mogao biti podrška u radu. & 1 & 2 & 3 & 4 & 5 \\
\hline 16. & Mislim da bi robot mogao da me razume. & 1 & 2 & 3 & 4 & 5 \\
\hline 17. & Osećao bih se ugodno u interakciji sa robotom. & 1 & 2 & 3 & 4 & 5 \\
\hline 18. & Mogao bih koristiti robota kada bi mi neko pomogao oko toga. & 1 & 2 & 3 & 4 & 5 \\
\hline 19. & Mogao bih koristiti robota bez ičije pomoći. & 1 & 2 & 3 & 4 & 5 \\
\hline 20. & Mogao bih koristiti robota kada bih imao dobru obuku za to. & 1 & 2 & 3 & 4 & 5 \\
\hline 21. & Robot bi me uplašio. & 1 & 2 & 3 & 4 & 5 \\
\hline 22. & Znao bih kako da koristim robota. & 1 & 2 & 3 & 4 & 5 \\
\hline 23. & $\begin{array}{l}\text { Znao bih kako da koristim robota kada bih imao jasno uputstvo za } \\
\text { upostrebu. }\end{array}$ & 1 & 2 & 3 & 4 & 5 \\
\hline 24. & Roboti su jako zanimljivi. & 1 & 2 & 3 & 4 & 5 \\
\hline 25. & Verujem da bi robot bio dobar prema meni. & 1 & 2 & 3 & 4 & 5 \\
\hline 26. & Verujem da bi me robot mogao razumeti. & 1 & 2 & 3 & 4 & 5 \\
\hline 27. & Mislim da je dobra ideja da robot učestvuje u terapije dece. & 1 & 2 & 3 & 4 & 5 \\
\hline 28. & Bojim se da bi robot mogao biti nepredvidljiv. & 1 & 2 & 3 & 4 & 5 \\
\hline 29. & Bojim se da bi moje dete polomilo ili oštetilo robota. & 1 & 2 & 3 & 4 & 5 \\
\hline 30. & Mislim da bi se mom detetu dopalo da bude u interakciji sa robotom. & 1 & 2 & 3 & 4 & 5 \\
\hline 31. & Mislim da bi moje dete volelo da dodirne robota. & 1 & 2 & 3 & 4 & 5 \\
\hline 32. & Robot mogao da dodatno pomogne terapiju mog deteta. & 1 & 2 & 3 & 4 & 5 \\
\hline 33. & $\begin{array}{l}\text { Rad sa robotom bi dodatno motivisao moje dete na učenje, igru, } \\
\text { vežbe... }\end{array}$ & 1 & 2 & 3 & 4 & 5 \\
\hline 34. & Moje dete bi se plašilo da radi sa robotom. & 1 & 2 & 3 & 4 & 5 \\
\hline 35. & Ne bih verovala robotu da samostalno radi terapiju sa mojim detetom. & 1 & 2 & 3 & 4 & 5 \\
\hline 36. & Robot neke aktivnosti u terapiji može uraditi bolje nego čovek. & 1 & 2 & 3 & 4 & 5 \\
\hline 37. & Voleo bih da moje dete ima priliku da bude u interakciji sa robotom. & 1 & 2 & 3 & 4 & 5 \\
\hline 38. & Volim filmove i knjige u kojima se pojavljuju roboti. & 1 & 2 & 3 & 4 & 5 \\
\hline 39. & Moje dete voli crtane filmove i priče u kojima se pojavljuju roboti. & 1 & 2 & 3 & 4 & 5 \\
\hline
\end{tabular}

